\title{
Hydraulically-operated Thin-layer Sampler for Sampling Heterogeneous Water Columns
}

\author{
Denis Y. Rogozin ${ }^{\mathrm{a}, *}$ and Andrey G. Degermendzhi, \\ a Institute of Biophysics, Siberian Branch of Russian Academy of Sciences, \\ Akademgorodok, Krasnoyarsk, 660036 Russia \\ ${ }^{b}$ Siberian Federal University, \\ 79 Svobodny, Krasnoyarsk, 660041 Russia $^{1}$
}

Received 2.06.2008, received in revised form 25.08.2008, accepted 27.08.2008

\begin{abstract}
A necessary condition for investigating microbial communities in chemocline zones of stratified waterbodies is high-precision sampling at a depth resolution of several centimeters. We have modified a multi-syringe sampler that is conventionally used by researchers for this purpose. The main distinctive feature of our sampler is that plungers are operated hydraulically rather than pneumatically and, thus, our sampler has the following advantages: (1) the plungers cannot move spontaneously, which ensures sampling adequacy, especially in deep-water sampling; (2) filling of the syringes with the sample can be monitored from a distance; (3) during storage, the internal volume of the syringe and the whole hydraulic system is aseptic (if 70\% ethanol is used as a working fluid), which is important if samples are to be used for microbiological tests. (4) the problem of sticking plungers is minimized, even after extended storage. Vertical sampling of the chemocline zones of meromictic lakes in Southern Siberia (Russia, Khakasia) at a depth resolution of $5 \mathrm{~cm}$ proves that the sampler is very reliable and simple to use.
\end{abstract}

Keywords: chemocline, microstratification, thin-layer sampler.

\section{Introduction}

In ecosystems of stratified waterbodies, a considerable contribution to material and energy fluxes is made by processes occurring in the zones of sharp physicochemical gradients of the water column, i.e. in the thermocline, the chemocline, and the picnocline. Much research has been done on planktonic communities and processes in the gradient zones of stratified lakes (e.g, Jorgensen et al., 1975; Overmann, 1997; Tonolla et al., 2003; and many others), but the structure and functions of these communities and their ecological role in the waterbodies are still underinvestigated. Moreover, stratified lakes are invariably attractive to researchers as "natural laboratories" in which different ecological niches of plankton microorganisms are formed along such physicochemical gradients as temperature, redox conditions, salinity, density, etc. It is well known that an adequate insight into biochemical processes and biota in the gradient zones of small lakes can only be provided by high-precision sampling at a depth resolution of several centimeters. It was reported that use of conventional samplers led to a

Corresponding author E-mail address: rogozin@ibp.ru

(c) Siberian Federal University. All rights reserved 
neglect of ecologically significant heterogeneities in the distribution of plankton microorganisms (Baker et al., 1985).

At the present time, the most frequently used devices for high-precision sampling are various modifications of the thin-layer pneumatic multisyringe sampler, which allows simultaneous collection of samples at different depths at intervals of 2-5 cm. This device was described in detail by Baker et al. (1985). Similar devices are successfully used to investigate stratified lakes (e.g., Overmann, 1997; Tonolla et al., 2003).

In our opinion, however, employment of pneumatic drive creates certain difficulties during sampling. For instance, when the sampler is submerged deep into the water, the air in the pneumatic drive system is inevitably compressed by the water column, which can force plungers to be drawn out too early and, hence, lead to inadequate sampling, particularly when it is performed at considerable depths (below $10 \mathrm{~m}$ ). This compression can be compensated for by pumping the air into the tubing while submerging the device to the target depth, in order to maintain enhanced internal pressure. This, however, can only be done if all connections in the pneumatic drive system are hermetically tight, which may be not the case for samplers that have already been used many times. Another difficulty may arise during sample collection. To take a sample, the researcher on board pumps the air out of the tubing, rarefying the air to the extent necessary for the plungers to be drawn out. If the movement of a plunger is constrained due to its wear and tear or misalignment, slight air rarefaction will not be enough for the plunger to be drawn out. If more air is pumped out to attain stronger rarefaction, the tubing will be compressed by the surrounding water and the plunger will not be able to move. As a result, the jammed syringe will not take any sample. To avoid these problems, we propose our modification of the multi-syringe sampler (Rogozin and Tolomeyev, 2005).

\section{Construction details}

As a prototype, we used the device described by Baker et al. (1985), but we replaced the pneumatic drive with the hydraulic one. Our sampler is schematically shown in Figure 1. The basis of the construction is the same row of transparent plastic syringes. The plastic shafts of the syringes are shortened, leaving only 1-3 cm behind the rubber plunger, which can then move up and down the barrel of syringe under the influence of pressure (Baker et al., 1985). Each syringe is fitted either with a rubber bung or, if large syringes are used, a metal lid with rubber encapsulation. Each bung or lid is fitted with a tap, connected to manifold running the length of the sampler.

The rear parts of the internal volumes of all syringes are interconnected via the manifold, which is tubing-connected to the pump held by the researcher on board (not shown in the picture). The whole of the internal volume of the tubing, manifold, and rear parts of the syringes is filled with the working fluid, which serves to transmit the hydraulic pressure to the syringe plungers. In order to collect a sample, the device is submerged to a target depth and, then, the working fluid is pumped out to reduce the pressure in the hydraulic circuit. The plungers of all syringes are drawn out (in the same way as in the pneumatically operated sampler) and the lake water is sucked into the front parts of the syringes through the nozzles.

In our modification we use 20 150-ml plastic disposable medical syringes (Janet's syringes, Tyumen, Russia) with shortened shafts and fitted with metal lids with rubber encapsulations; the distance between the nozzles is $5 \mathrm{~cm}$ (Fig. 1). All the metal details are made of stainless steel and titanium (Institute of Biophysics SB RAS). 

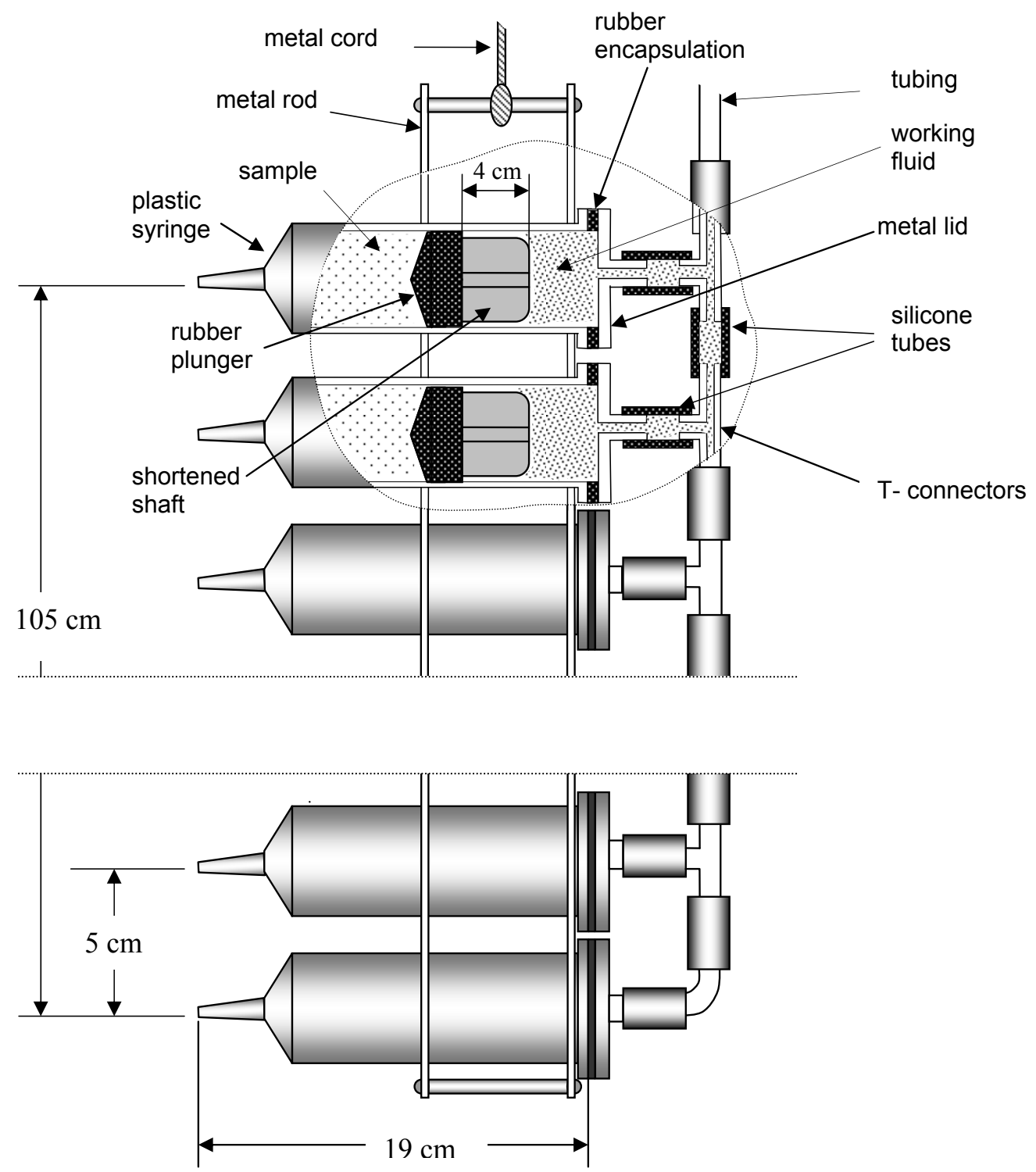

Fig. 1. Scheme of hydraulically-operated thin-layer sampler 


\section{Performance in the field}

Hydrostatic water pressure depends on the column height and density of the fluid and does not depend on the volume and shape of the water column. This phenomenon is known as the "hydrostatic paradox". Hence, in our case, the hydrostatic pressure of the working fluid column on the plunger in the rear part of the syringe is equal to the hydrostatic pressure of the lake water on the same plunger at the nozzle side. Thus, plungers cannot possibly be drawn out spontaneously, to whatever depth the device is submerged. Hence, our device can sample rather deep water layers, where the pneumatically operated sampler can hardly be used. The pressures are still slightly different due to differences in densities of the working fluid and the lake water and because the pump is installed on board, somewhat higher than the level of the lake surface. But our experience proved that the pressure difference is negligibly small and does not create any sampling-related difficulties.

The working fluid can be water, but we prefer to use a $50-70 \%$ ethanol. Firstly, this prevents the hydraulic system from freezing when the device is transported to the sampling position at below-zero $\left({ }^{\circ} \mathrm{C}\right)$ temperatures. Secondly, this is a protective factor against bio-fouling of the internal volumes of the syringes and the hydraulic system, which is important during extended storage. Interestingly, the authors of the pneumatic prototype advise storing the sampler full of water, to minimize the problem of sticking plungers (Baker et al., 1985). Our sampler is always full of liquid and, so, the probability of sticking is naturally low. Experience shows that alcohol solution does not significantly decrease the smoothness of plungers' movement if one uses standard plastic medical syringes with rubber-tipped plungers. There is no need to apply any lubricant to the plungers.
Immediately after the sample is collected and the device is taken out of the water, we put a hermetic rubber cap on the nozzle of every syringe, to prevent samples from contacting the environment. As a rule, samples should be expelled out of syringes one at a time, in any order. To take out a sample, one should simply remove the nozzle cap of a selected syringe and then pump the working fluid back into the hydraulic system through the tubing using the same (or another) pump. So, each time, only the plunger of the open-nozzle syringe will move. When all samples are expelled, the plungers of all syringes are fully depressed; the syringes are then filled with the working fluid, and the sampler is ready to be used again.

Experience shows that ingress of a small amount of air into the hydraulic circuit does not affect the operation of the sampler. Moreover, during sampling, air bubbles that have accidentally entered the system (e.g., with the pumped-in working fluid) move upward in the tubing, tending to surface, and gradually leave the system together with the pumped-out fluid. Another important advantage of the hydraulically-operated sampler is that the volume of the pumped-out working fluid is always equal to the volume of the collected water. Hence, based on the volume of the working fluid pumped out during sampling, the researcher on board can always deduce how many syringes have been filled with the water. This will prevent lifting the sampler before all the syringes are filled with the water if, for some reason, the plungers of one or several syringes move too slowly.

As a pump, we use a 150-ml medical syringe (Janet's syringe, Tyumen, Russia). The volume of the working fluid to be pumped out (in) during sample collection (extraction) is larger than the volume of the syringe and we have to disconnect the syringe from time to time to expel or take in the working fluid. When the syringe is disconnected, we prevent the working fluid from flowing 
out and/or the air from entering the system by hand-bending the tubing 180 degrees. Using the syringe rather than the pump makes the sampling procedure just slightly longer, but the reliability of the sampler is increased significantly and we avoid technical difficulties related to usage of the pump in the field conditions.

\section{Examples of data collected with}

\section{hydraulically-operated multi-syringe sampler}

We use this sampler to study the structure of planktonic microbial communities in the chemocline regions of meromictic lakes. As an example of the data obtained using our sampler, we show the vertical distributions of physicochemical properties of the water and abundance of phototrophic bacteria in Lake Shunet, which is situated in the south of Siberia (Khakassia, Russia) (Fig. 2). Mineral content of the water in this lake is distributed very non-uniformly in the water column, which causes sharp gradients of physicochemical properties of the water in the chemocline region and leads to considerable accumulation of sulfide in the monimolimnion. The chemocline zone of this lake is rather close to the surface (about $5 \mathrm{~m}$ down) and, thus, there is enough light there for phototrophic anoxic bacteria to develop abundantly.

Pigment analysis and direct counts using reflected-light microscopy revealed steady microstratification of purple and green sulfur bacteria, which persists in the chemocline of this

○ Purple Sulfur Bacteria, $10^{6}(\mathbf{A}), 10^{7}(B)$ cell $\mathrm{ml}^{-1}$;

- Green Sulfur Bacteria, $10^{6}$ cell $\mathrm{ml}^{-1}$;

$\triangle$ Oxygen, $\mathrm{mg} \mathrm{I}^{-1}$
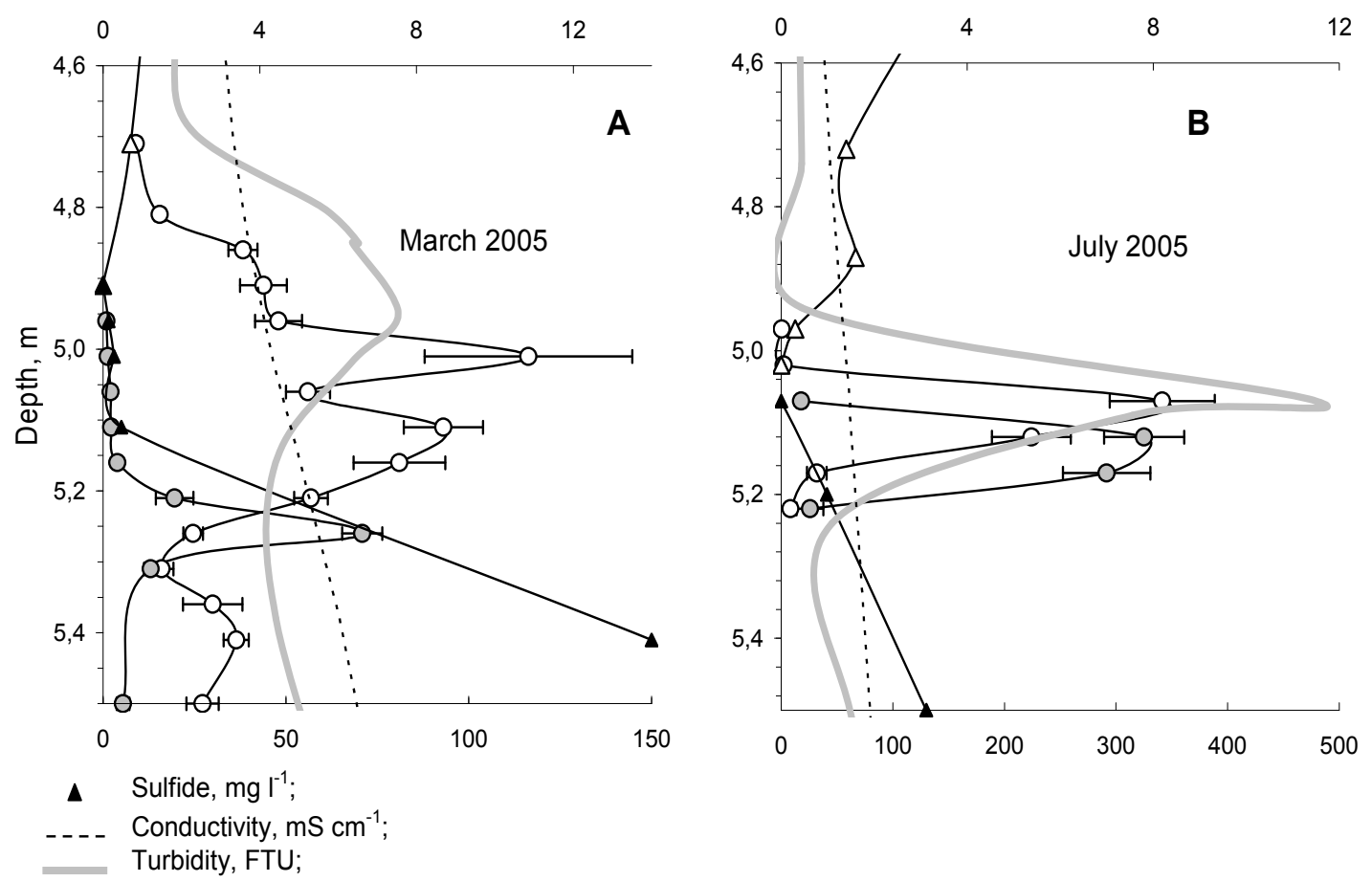

Fig. 2. Vertical profiles of phototrophic sulfur bacteria and physicochemical characteristics in chemocline zone of Shunet Lake (South Siberia, Russia). Profiles of bacterial abundance and sulfide were obtained from samples taken with hydraulically-operated thin-layer sampler shown in Fig.1. Oxygen, conductivity and turbidity profiles were obtained with submersible multi-channel probe (Hydrolab, Austin, Texas, USA) 
lake throughout the year, even under ice (Fig. 2a). The number of phototrophic bacteria in Fig. 2 are expressed as mean $\pm \mathrm{SE}$.

Throughout the year, green sulfur bacteria (GSB) form a numerical peak a few centimeters below the numerical peak of purple sulfur bacteria (PSB) (Fig. 2). The PSB numerical peaks were found at the same depth as turbidity peaks, registered independently, using a submersible multi-channel probe (Hydrolab DATA Sonde 4, Austin, Texas, USA) (Fig. 2). In summer, PSB formed a "purple" layer about $5 \mathrm{~cm}$ thick in the chemocline of Lake Shunet; this layer was visible to the eye in one or two syringes of our sampler. The PSB abundance in that layer was extremely high - about $10^{8}$ cell $\mathrm{ml}^{-1}$. So far, a similarly high abundance of PSB has only been reported for the chemocline of Lake Mahoney (Canada) (Overmann, 1997).

Evidently, the numerical profiles shown in Figure 2 would be undetected by a wider sampling interval. Microstratification of phyto-, bacterio-, and protozooplankton occurring in the regions of sharp gradients of physicochemical conditions in the water column of stratified lakes can only be registered by precision sampling. The best depth resolution can be obtained using multi-syringe samplers, both pneumatic (e.g., described by Baker et al., 1985) and hydraulicallyoperated ones, such as the sampler proposed in this paper. An alternative to precision sampling is pumping, which is also frequently used in studies of stratified lakes (e.g., Jorgensen et al.,
1979). However, A.L. Baker and his coauthors (1985) showed experimentally in stratified aquaria that pumping yields lower resolution than multi-syringe samplers, as the flow rate and the large total volume extracted with the pumping inevitably leads to disturbance of layering.

\section{Conclusion}

Thus, our sampler has the following advantages over the well-known thin-layer pneumatic multi-syringe samplers:

1. the plungers cannot move spontaneously, which ensures sampling adequacy, especially in deep-water sampling (deeper than $10 \mathrm{~m}$ );

2. filling of the syringes with the sample can be monitored from a distance;

3. during storage, the internal volume of the syringe and the whole hydraulic system is aseptic (if 70\% ethanol is used as a working fluid), which is important if samples are to be used for microbiological tests.

4. the problem of sticking plungers is minimized, even after extended storage.

The proposed sampler is very reliable. We have used the modification shown in Fig. 1 for five years to investigate the micro-stratification of microbial communities in the chemocline zones of the meromictic lakes Shira and Shunet (Russia, Southern Siberia) (Rogozin et al., 2005) and a number of other stratified waterbodies. The operation of the samplers has been faultless and no technical service has been provided.

\section{Acknowledgements}

We thank Dr. A.P. Tolomeyev for assistance in preparing drawings of the sampler units and Dr. D.B. Kosolapov for useful discussions. We also thank M.M. Satarov for making the metal components of the device. This work was partly supported by the Russian Foundation for Basic Research, Grant 05-05-89002, by Joint Grant No. 07-04-96801 of Krasnoyarsk Regional Scientific Foundation and Russian Foundation for Basic Research, by the Netherlands Organization for Scientific Research, Grant 047.011.2004.030, by award No. PG07-002-1 of the Ministry of Education and Sciences of Russian 
Federation and U.S. Civilian Research \& Development Foundation for the Independent States of the Former Soviet Union (CRDF), and by Siberian Branch of Russian Academy of Sciences, Integrative Project No. 24.

\section{References}

Baker A.L., Baker K.K., Tyler P.A. (1985) A family of pneumatically-operated thin layer samplers for replicate sampling of heterogeneous water columns. Hydrobiologia 122: 207-211.

Jorgensen B.B., Kuenen J.G., Cohen Y. (1979) Microbial transformations of sulfur compounds in a stratified lake (Solar Lake, Sinai). Limnol. Oceanogr 24: 799-822.

Overmann J. (1997) Mahoney Lake: a case study of the ecological significance of phototrophic sulfur bacteria. In: Jones J.G., (ed.) Advance in microbial ecology, Vol. 15, Plenum Press, New York, p. 251-288.

Rogozin D.Y., Pimenov N.V., Kosolapov D.B., Chan'kovskaya Y.V., Degermendzhy A.G. (2005) Thin-layer vertical distributions of purple sulfur bacteria in chemocline zones of meromictic Lakes Shira and Shunet (Khakassia). Doklady Biological Sciences 400: 54-56. (Translated from Doklady Akademii Nauk (2005) 400: 426-429).

Rogozin D.Y., Tolomeyev A.P. (2005) Stratifikatsionnyi batometr vysokogo razresheniya s gidravlicheskim upravleniyem. (High-performance stratification sampler with hydraulic remote control). RF patent No. 2244282, 25 March 2003 (In Russian).

Tonolla M., Peduzzi S., Hahn D., Peduzzi R. (2003) Spatio-temporal distribution of phototrophic sulfur bacteria in the chemocline of meromictic Lake Cadagno (Switzerland). FEMS. Microbiol. Ecol. 43: 89-98. 